\title{
Medicinen och människovärdet
}

\author{
CARL-MAGNUS STOLT
}

\begin{abstract}
Det finns ett uppenbart behov av att resonera om vardagsetiskt förhaillningssätt i sjukvården. Filosofisk begreppsanalys och idéhistoria är i sammanhanget viktiga redskap för att fördjupa resonemangen. Denna artikel är ett försök till en analys av de vanligaste och viktigaste vardagsetiska begreppen. Vidare relateras dessa till en modell för medicinen som kunskapssystem. Slutligen fokuseras runt humanism som en ideologi för medicin och sjukvård.
\end{abstract}

\begin{abstract}
Bakgrund
Sedan 1800-talets senare hälft befinner sig medicinen i ett naturvetenskapligt paradigm. De tongivande medicinska auktoriteterna under 1800-talets slut, som exempelvis Claude Bernard, angav inte bara villkoren för experimentell medicinsk forskning utan demonstrerade också tydligt en materialistism och determinism. Vetenskapssyn har stor betydelse för vilken människosyn man har. Den naturvetenskapliga medicinens metod har sedan dess inneburit objektivisering, kvantifiering och analytisk fragmentering. Subjektet och helhetsperspektivet har underordnad betydelse. Räckvidden av de medicinskt-naturvetenskapliga influenserna under 1800-talets slut var bety-
\end{abstract}

Stolt är professor i humanistisk medicin, Karolinska Institutet, Stockholm och chefläkare, Södra Älvsborgs Sjukhus, Borås. dande, dels för 1900-talets medicin och dels gränsöverskridande mot ex vis skönlitteraturens realism och naturalism.

Det antika medicinska arvet, främst det grekiska, betonade i högre omfattning behovet av en holism, och kan därför sägas varit mer humanistisk. Med språk från den tyske filosofen Wilhelm Dilthey (1833-1911) kan man säga att målet för medicinsk naturvetenskap är förklaring. Förklaring av sjukdom och hälsa, förklaring av symtom och terapeutisk intervention. Men när medicinen tilllämpas i praktisk sjukvård är detta inte tillräckligt. Eftersom man inte möter objektiva och rakt igenom mätbara storheter så måste en dimension av förståelse för hela personen komplettera förklaringen. Förståelsen utövas i vårdarens konst, som är komplementär till den vetenskapliga tillämpningen.

Gränsen mellan förklaring och förståelse är flytande. 


\section{Människosyn och människovärde}

Skall man resonera om medicinen och människans värdighet finns det ett antal begrepp att utgå ifrån. Världsbild och vetenskapssyn påverkar eller styr hur vi uppfattar och ser på människan. Ibland har man velat åtskilja människouppfattning och människosyn. Det förstnämnda är då, som Nordenfelt (1991) påtalat, blott en del av det sistnämnda, nämligen den del som inkluderar (natur)vetenskapliga fakta om människan. Vad består vi av? Hur fungerar vi som biologiska organismer? I människosynen finns därutöver värderande, normativa element.

Alla dessa övergripande begrepp påverkas av mer eller mindre uppenbara ideologier. Dessa kan vara politiska, religiösa, filosofiska eller kommersiella osv. Den ideologi som lyfts fram i denna uppsats är humanismen, eftersom den tycks vara allmänt åberopad i dagens medicin och sjukvård. Sammanfattningen är att den människosyn vi har påverkas av rådande vetenskapssyn och bakomliggande ideologier. Människosyn kan ses som en övergripande term. En del i människosynen är uppfattningen om människovärdet. Har alla människor lika värde? Är människovärdet absolut eller relativt? De flesta tycks idag anse att alla människor har samma människovärde, dvs man hävdar att detta är ett normativt axiom, som inte kan bevisas genom empiri eller vetenskaplig undersökning. Ett absolut människovärde är konstant och oföränderligt. Ett relativt människovärde varierar och kanske även är påverkbart.

Statens medicinsk-etiska råd (1993) har $i$ en debattskrift resonerat om det faktum att människor är olika värdefulla (kompetenta, dugliga) inte behöver betyda att man förespråkar ett relativt människovärde. Att någon är värdefull måste relateras till situationen. Men frågan blir svårare om man tänker sig en människa som inte i någon situation eller sammanhang anses värdefull. Beskriver man en sådan person som värdelös? Om det är samma sak som lågt människovärde så förespråkar man ett relativt människovärde.

Filosofen Dan Egonsson (1999) använder termerna privat och socialt människovärde. Med privat människovärde menar han det värde man själv anser sig ha, och med socialt människovärde det värde man har för andra. Det sistnämnda blir därför ungefär detsamma som "värdefullhet « ur andras behovssynvinkel. Problemet löses inte med denna distinktion. Ett privat människovärde kan exempelvis vara förminskat av ringhetsidéer vid depression eller patologiskt uppförstorat (på andras bekostnad) vid megalomani. Ett socialt människovärde utgår å andra sidan helt från ett aktörsperspektiv. Förespråkar man ett absolut och icke-kvantifierbart lika människovärde, så är detta objektivt i bemärkelsen att det är oberoende av kontextuellt sammanhang. För att komma bort från det till kvantifiering inbjudande ordet »värde« så har istället ordet människovärdighet föreslagits.

Tankarna går då lätt till den italienske renässanshumanisten Pico della Mirandolas berömda Tal om människans värdighet från 1488. Primärt tilltalad av denna term som en icke-kvantifierande synonym för ett absolut och oföränderligt människovärde, finner man dock att "värdighet « mer är att se som en egenskap, alltså något snarare knutet

Socialvetenskaplig tidskrift nr 1-2 • 2001 
till ett aktörsperspektiv än ett personperspektiv. Med värdighet avses ett beteende hos person eller karaktären av det bemötande man ger personen. Värdighet handlar om agerande. Man uppträder värdigt, man bemöter patienten värdigt och man kanske bibehåller sin värdighet exempelvis i döendet. Värdighet är med andra ord inget konstant utan föränderligt. Pico della Mirandolas tal hette på latin De hominis dignitate. Ordet dignitet har innebörden värde och rang och en dignitär är en överhetsperson av tyngd. Värdighet är alltså en graderbar egenskap och beteende. Förespråkar man att alla människor har samma människovärde föreslår jag att man talar om ett absolutmänniskovärde. En förespråkare för alla människors lika värde var filosofen Immanuel Kant (1724-1804) som med sitt begrepp Menschenwürde betonade att människans värde ligger i det moraliska subjektets autonomi och vidare att varje människa är ett mål i sig, inte enbart ett medel.

\section{Autonomi och integritet}

Det råder en viss förvirring i synen på om orden människovärde och integritet betyder samma sak. I dagens vårdetiska debatt tycks många anse att så är fallet. Många förstår sålunda inte den distinktion som Socialstyrelsen (1996) gör i en författningssamling, där det sägs att vården skall inrättas så att "patientens värdighet och integritet tillgodoses" (min kursivering), dvs. man gör klart att orden har olika innebörd. Ordet integritets latinska ursprung hade innebörden hel, oskadad etc. Ordets moderna historia är dock kort, och i dess ursprung ligger bety- delsen "rätt till egendom». Idéhistorikern Karin Johannisson (i Strömberg, 1999) har definierat integritet som »en personlig sfär där ingen utan tillstånd har tillträde».

I Svenska Akademiens ordlista ges ordet förklaringen "orubbat tillstånd, okränkbarhet, oberoende«. Men integriteten kan kränkas, och i själva verket är kränkning något som ständigt riskerar ske i vårdens vardag. Drabbas man exempelvis av en hjärnblödning, hamnar på sjukhus och förlorar förmågan att sköta sin personliga hygien så gör vårdpersonalen ett intrång i denna personliga sfär, ibland endast med patientens förmodade samtycke. Men att kränka patientens integritet där inget samtycke erhålles betyder såvitt jag förstår antingen tvångsvård eller att man anser att patienten man möter inte har samma människovärde som till exempel jag själv. I fallet med tvångsvård ikläder vi oss ett förmynderi pga. att patienten inte anses beslutskapabel.

Steget till nästa begrepp, autonomi, är inte långt men inte heller enkelt. Det finns samband mellan integritet och autonomi. Innebörden i autonomin är dock mer tydlig än när det gäller integritetsbegreppet. Autonomi betyder självbestämmande, dvs.idetta sammanhang patientens rätt att fatta egna beslut och veta sitt eget bästa. Andra innebörder i ordet autonomi är självtillåtande och självstyre. Historiskt går begreppet främst tillbaka till Imannuel Kant och måste då relateras till rätten till frihet. Autonomi och integritet har nära samband, vilka kan beskrivas på olika sätt. Sundström (1996) har tecknat upp fyra typer av etisk relevant integritet:

1. Kroppslig/biologisk/fysiologisk integritet. 
2. Psykisk/mental integritet

3. Viljeintegritet

4. Existentiell integritet.

Kanske är denna uppdelning väl teoretisk, men det är fruktbart att se autonomi som detsamma som vilje- och existentiell integritet (typ 3 och 4 enligt Sundströms indelning). På så sätt möts begreppen autonomi och integritet. Men relationen mellan autonomi och integritet är mer komplex. Autonomin kopplas naturligt till funktioner. För att kunna utöva sitt självbestämmande så måste ha förmågan till det. Av detta följer att autonomin kan vara nedsatt (ex.vis vid funktionshinder) eller helt borta (ex.vis vid medvetslös). Oavsett autonomins variationer kan man dock hävda ett konstant människovärdet, dvs. samma respekt för alla människors rätt till integritet. Men ser man människovärdet som en relativ storhet, så är det alltså inte samma för alla människor, utan måste relateras till något såsom funktioner, ras, socialgrupp etc. I den vårdetiska diskussionen är det vanligt att fundera över om graden av autonomi påverkar människovärdet, eller med andra ord om en människas sjukdom påverkar hennes människovärde. Ett relativt, växlande människovärde är knutet till om man ser på människan som aktör snarare än som person. Denna skillnad i människosyn betingas av om man ser människan som en storhet i sig eller som någon som kan agera.

Aktörsperspektivet tar sikte på en människas funktioner medan personperspektivet är oberoende av vad en människa kan göra. Autonomibegreppet hänger med andra ord samman med aktörsperspektivet. En relativisering av människovärdet kan leda till att man endast anser att en beslutskapabel, frisk och välfungerande människa har full autonomi och fullt människovärde.

Motsatsenär ett renodlat personperspektiv. Då ser man att autonomin kan variera, men att människovärdet oavsett detta är absolut. Respekten för integriteten är då alltid bevarad och om man måste röra sig in patientens personliga sfär så måste samtyckeinhämtas. Personbegreppetshistoriska rötter går, som Horgby (1995) utrett, att spåra till antikens teatrar där skådespelarens mask bar denna beteckning. Genom (per) denna mask hördes (sonare) rösten. Personbegreppet övertogs sedan av kristendomen. En utmaning för vårdandets konst i praktisk sjukvård är att förstå patienter, som man uppfattar som motbjudande. Kanske har de begått onda, motbjudande handlingar. Men vårdandets konst syftar till förståelse då är personen viktigare än aktören. Med ett renodlat aktörsperspektiv är det svårt eller omöjligt att förstå patienter inom exempelvis rättspsykiatrin. Man måste med andra ord se bortom en människas handlingar. Kopplingen mellan dygdetik och personbegreppet liksom mellan nyttoetiken och aktörsbegreppet är uppenbar. Relationen mellan aktör och person kan snarast uttryckas så att alla människor alltid är personer men bara ibland aktörer.

\section{Människoblivandet}

En springande punkt när det gäller människovärde är frågan om människoblivandet. När blir man människa och när upphör man att vara det? Finns det varelser av släktet homo sapiens som inte betraktas som män- 
niskor, och alltså inte har rätt till lika människovärde? Återigen är det lätt att med tydliga historiska exempel från diktaturer och krigssituationer hitta att man besvarat den provokativa frågan jakande och handlat därefter.

Talar man om människoblivande som en process blir följande vårdetiska frågor viktiga:

Har en ofödd fullt människovärdet? En rullstolsbunden? En socialt utslagen missbrukare? En medvetslös? En döende? En cancersjuk? En döv? En 98-åring? Ett foster har ju uppenbart nedsatt autonomi. Men skillnaden i autonomi mellan ett foster och en nyfödd är obetydlig. När har en (frisk) människa nått möjlighet till full autonomi? Klarar sig en 5-åring på egen hand? Är det först då man blir människa och får sitt fulla människovärde?

Läkaren och författaren P-C Jersild (1993) har redovisat sin syn på människoblivandet som ett antal trappsteg, och under denna fas använder han inte begreppet människovärde utan skyddsvärde. Kan man tilllämpa detta resonemang i livets slutskede? Är en döende människa, utan möjlighet att utöva ett uns av autonomi, inte längre människa? Eller är det så att även människoupphörandet är ett antal trappsteg där man till sist inte har ett människovärde utan möjligen ett skyddsvärde?

En nyttoetiker som den svenske filosofen Torbjörn Tännsjö (1990) menar att idén om allas lika värde endast är rimlig som en tanke om opartiskhet, dvs. att man inte skall dra fördelar av samhällsställning och liknande när man exempelvis söker vård. Ett liv som frisk mer värt än ett liv som sjuk, hävdar han, med följdfrågan: „Varför skulle vi annars sträva efter att bota sjukdomar?». Men en strävan att öka lyckan, till exempel genom att motverka lidande (behandla sjukdomar), kan som jag ser det emellertid frikopplas från axiomet om allas lika värde. Endast tanken på ett absolut människovärde, ej sammankopplat med funktionsoch aktörsperspektivet, innebär att man undviker att värdemässigt degradera sjuka och handikappade. Men en mångfald av etiska uppfattningar är väsentlig, ur den stiger dialogen och insikten om att ingen åsiktkanåberopa tolkningsföreträde. Kanske kan man urskilja tre alternativ vad gäller människovärde och människoblivande:

- människan har ett absolut människovärde från konceptionen till döden.

- människan blir människa gradvis, och får via skyddsvärde absolut människovärde efter viss tid

- människan har ett relativt människovärde som bestäms av funktion och tillstånd.

Det går inte att frikoppla resonemang om människovärde i medicinen från begreppen mänskliga rättigheter samt mänskligt lidande. Filosofen Ingemar Hedenius (1982) är ofta citerad när det gäller ett försök till definition av människovärde och mänskliga rättigheter. Sammanfattningen av hans definition är att alla människor har samma rätt till en människovärdig tillvaro. Mänskliga rättigheter har således ett nära samband med ett resonemang om människovärde. Men uttrycket människovärdig tillvaro kan ha olika innehåll beroende av ålder och grad av hälsa. Det viktiga i sammanhanget är att utgå från vad personen själv uppfattar som människovärdigt. Det betyder inte nödvändigtvis att människovärdet måste relativise- 
ras. I sjukvården är detta en ständigt närvarande etisk utmaning. Den statliga prioriteringsutredningen (SOU 1993) underströk att kronologiska åldersgränser inte skulle tillämpas vid ställningstagande till medicinska åtgärder. I detta instämmer säkert de flesta läkare rent principiellt, men något större stöd $i$ vårdvardagen är utredningen knappast på den punkten. I praktiken resonerar man ofta om vad som, relaterat till ålder och hälsotillstånd, är rimligt och människovärdigt . Livet är inte så instrumentellt att det t.ex. bara är att lägga någon i respirator utan man gör alltid en sammanvägd medicinsk totalbedömning, i vilken självklart åldern ingår som en viktig variabel. Det betyder inte att man åldersdiskriminerar och det behöver heller inte betyda att man relativiserar människovärdet. Det som varierar är snarare vad man anser människovärdigt. Intensivvård åt en 30-åring kan vara det enda värdiga i en kritisk situation men samma intensivvård åt en 95-åring kan vara ovärdigt. Än mer komplicerat blir det om man konstaterar att samma intensivvård åt 30-åringen också kan vara ovärdig, om utsikterna att de skall lyckas är minimala och patienten uttryckt önskemål om att få slippa. Dennis Mc Kerlie (1992) har lämnat belysande bidrag till de etiska resonemangen om ålder och rättvisa.

\section{Kränkning}

Autonomi och integritet blir tommabegrepp om man inte lyfter fram hoten mot dem. Det viktigaste hotet kan vi sammanfattande benämna kränkning. Kränkning innebär att man inte respekterar autonomi, integritet eller människovärde, dvs. att man inte respekterar personen. Det är viktigt att komma ihåg att kränkning kan karaktäriseras som antingen omedveten eller medveten, samt som systematisk eller spontan. Om något skall karaktäriseras som en kränkning är också en definitionsfråga. Hur definierar vi en kränkning? Uppenbart påverkas bedömningen av tidsanda och kulturella, samhälleliga sammanhang samt även inom-medicinska faktorer. En patient som känner sig kränkt kan protestera och anmäla. Det är tydliga signaler, men kanske och troligen finns det många som upplever sig kränkta utan att visa det. Hur vet vårdaren då om en kränkning ägt rum, särskilt om vårdaren själv varit omedveten om den? Vidare är det ingalunda ovanligt att patienten själv är omedveten om en kränkning. Tänk er exempelvis en medvetslös patient som utsätts för otillbörlig, sexuellt laddad beröring. Det rör sig då om en kanske spontan men medveten kränkning från vårdarens sida.

Man kan också tänka sig en situation där såväl vårdare som patient bådaär omedvetna om kränkningen, och där vårdaren upprepar kränkningen systematiskt (och kanske som uttryck för ett systemfel). Spelar det då någon roll om en utanförstående objektiv betraktare ser kränkningen? Som jag ser det bör begreppet kränkning hamna i fokus för den vårdetiska forskningen. Det finns ett motsatsförhållande mellan kränkning och bekräftelse. Misslyckas man med att bekräfta patienten som person innebär det en risk för kränkning. Som jag ser det är bekräftelse av personen det som kännetecknar en humanistisk färgad medicin. Medicinen som vetenskap får ju sin mening först i tillämpningen, och tillämpningen sker i

Socialvetenskaplig tidskrift nr 1-2 • 2001 
mötet mellan patient och vårdare. Problemet uppstår om medicinen i sin vetenskapssyn - och därmed i sin människosyn - systematiskt inte ser och bekräftar människan som person och helhet. En person inskolad i en vetenskap med ett icke-bekräftande förhållningssätt riskerar i sin praktik att omedvetet kränka sin patient. Inom vårdvetenskapen talar man ibland inte bara om vårdrelationer utan också om icke-vårdande relationer. Vårdrelationen ur patientens perspektiv kan i det sistnämnda fallet vara livförstörande och kränkande eller livsinskränkande och okänslig. Den kan också vara livsneutral - om det finns brist på intresse från vårdarens sida.

\section{Paternalism versus autonomi}

Till denna parad av viktiga begrepp i vårdens vardagsetik skall föras den ur vårdarens perspektiv så viktiga axeln mellan å ena sidan paternalism (förmyndarskap) och på den andra respekt för patientens autonomi. Det behövs ingen mer avancerad historisk analys för att finna exempel på att en paternalistisk hållning har varit vanlig i sjukvården. Att så varit fallet hänger samman med flera faktorer där social kontext, utformning av medicinsk etik, sjukvårdens hierarkiska organisation, sjukvårdens syfte och vårdarens expertroll kanskeär de viktigaste. Sjukvårdens syfte är ju att hjälpa patienten och läkarens kunskap och erfarenhet gör att det är oerhört lätt att tro sig veta vad som är bäst för patienten. I viss mening vet man också bäst, sett ur ett generellt perspektiv, men icke relaterat till en unik person. Det gör att begreppen autonomi och paterna- lism dynamiskt balanserar mot varandra i sjukvårdens komplexa vardagsetik. Det som sysselsatt mitt tänkande mest i det avseendet är om utövandet av den för förståelsen nödvändiga läkekonsten (med inslag av placebo, intuition, bekräftande beröring och skapande av tillitsfullt förtroende) innebär ett visst mått av paternalism som därmed riskerar inskränka patientens autonomi. Samtliga historiska läkargestalter som fördjupat tänkandet runt innebörden i läkekonsten kan nog alla med efterklokhet beskyllas för ett inslag av paternalism.

Historiskt skulle man vidare kunna beskriva delar av den slutna psykiatriska vården som ett förmyndarskap för att skydda patientens integritet som frisk - på bekostnad av autonomin och integriteten som sjuk. Distinktionen om personen är beslutskapabel blir i sammanhanget avgörande. Information, i betydelsen övertalning, påtryckning, manipulation - innebär en risk för kränkning av självbestämmandet. Jämför vidare med moraliserandet runt "livsstilssjukdomarı och om det önskvärda i att förändra beteenden. Historisktär detta tydligt främst från sekelskiftets hälsoreligion, med läkaren och författaren Henrik Berg som framträdande tidstypisk ideolog.

\section{En modell för medicinen}

När man resonerar om dessa grundläggande vardagsetiska begrepp ute i sjukvården har det känts angeläget att foga in dem i en modell för medicinen som kunskapssystem och praktik. Anledningen till detta är stor eftersom det idag finns en betydande begreppsförvirring och motsätt- 
ningar mellan olika vetenskapsgrenar och yrkeskategorier - som dock alla har det gemensamt att de ägnar sig åt hälsa och sjukdom. Vidare finns det anledning att analysera vårdens praxis - och försöka klargöra dess beståndsdelar. Slutligen måste vi fortlöpande analysera vårdetikens begrepp och förankra dem i en modell som gör dem tydliga (men inte entydiga) och skänker dem vetenskaplig tyngd. Artikelförfattaren (1999) har tidigare presenterat tankar om en modell för medicinen som kunskapssystem.

Jag ser ordet medicin som ett lämpligt överordnat begrepp. Dess djupaste syfte är att beskriva, förklara och förstå människan i hälsa och sjukdom i syfte att hjälpa. Denna definition är kanske för vid, men kan användas i brist på bättre. I sin vårdpraktik är medicinen både en konst och en vetenskap. Den konst som utövas är vårdandets konst (läkekonst), som är den personliga förståelsekonst som vårdaren, oavsett yrke, utövar i relationen till patienten. vetenskap som vårdaren tillämpar kan vi följaktligen kalla medicinsk vetenskap, och det är där som begreppsförvirringen blir uppenbar. Som nämnts inledningsvis är den dominerande medicinska vetenskapen naturvetenskaplig sedan knappt 150 år. Naturvetenskaplig medicin innebär en stringent vetenskaplig metod som medfört epokgörande framsteg i kampen mot lidande. Naturvetenskaplig medicin har etablerats så kraftfullt och framgångsrikt att många ser den som en synonym till medicinsk vetenskap. Men jag ser medicinsk vetenskap som ett större begrepp än medicinsk naturvetenskap. Men ser man inte den skillnaden måste exempelvis vårdvetare med skärpa hävda att deras disciplin inte tillhör den medicinska vetenskapen. Ser vi till medicinens syfte - att beskriva, förklara och förstå i syfte att hjälpa - så är det för många uppenbart att naturvetenskaplig medicin behöver komplement. Eller har naturvetenskaplig medicin möjligheter att inte bara förklara utan också förstå en människas väsen? Detta beror på hur man ser på och uppfattar människan som fenomen - det mänskliga. Kan naturvetenskaplig metod ge heltäckande och komplett kunskap av alla aspekter av det mänskliga, även sådant som kallas människans etik, metafysik, mysterium och poesi? Svarar man jakande på denna fråga räcker det med naturvetenskaplig medicin. Om svaret på samma fråga blir nekande måste man söka komplementära vetenskapliga metoder. Dessa kan sammanfattas under benämningen medicinsk humanvetenskap. Som jag ser det inryms där väsentliga delar av vårdvetenskap, psykiatri, medicinsk psykologi, folkhälsovetenskap, medicinsk etik, medicinsk idéhistoria, medicinsk sociologi, medicinsk pedagogik, medicinsk filosofi $\mathrm{m}$ fl discipliner. Medicinsk humanvetenskap är kvalitativ i sin ansats och metod. Dess studieobjekt är oftast inte så lätta (eller kanske omöjliga) att kvantifiera och de är inte sällan subjekt. Ett centralt studieobjekt för medicinsk humanvetenskap är patient-vårdar-relationen och hur vårdandets konst utövas.

Givetvis kan man gå vidare och fråga sig om medicinsk vetenskap, som alltså enligt mitt synsätt består av medicinsk naturvetenskap ochmedicinskhumanvetenskap, kan ge full kunskap om alla mänskliga fenomen runt hälsa och sjukdom, det som jag ovan kallade människans mysterium? Kanske är det så att skönlitteratur och annan konst 
- som alla beskriver och uttrycker mänskliga känslor, alltid är ett komplement till medicinsk vetenskap. Det finns forskning om skönlitteratur som klinisk kunskapskälla och nyligen gav Karolinska Institutet (Böttiger och Nordenström, 1999) ut en skönlitterär antologi. Författaren Ezra Pound (1975) har i sina Litterära essäer varit inne på detta när han skriver:

"De olika konstarterna, litteraturen, poesin, är vetenskaper lika väl som kemin är vetenskap. Deras uppgift är att analysera människan, människosläktet och individen. Kemins uppgift är att analysera hur materien är sammansatt. Konsten ger oss en stor procent av de bestående och ovederläggliga erfarenheterna om den mänskliga naturen, den andliga människan, människan sedd som en tänkande och kännande varelse. Dess domän börjar där den medicinska vetenskapens tar slut, eller snarare skjuter den en bit in på medicinens område. De två konstarterna går över varandras gränser.

Medicinen lär oss att människan trivs bäst med en lämplig dosering hygien, luft och sol. Konsten lär oss att människan är nyckfull, att den ena människan inte är lik den andra».

\section{Humanistisk medicin}

Ämnesansatsen humanistisk medicin är en medicinsk humanvetenskap. Den sätter personen i centrum för sin forskning. Genom att använda prefixet humanistisk betonas att detta ämne i den vetenskapliga medicinska familjen studerar den enskilda människan som helhet. Ledermann (1986) förespråkar benämningen holistisk medicin. I detta sammanhang kan man också som Sjöstrand (1998) påtalat se holism och humanism som försök att ta tillvara på och åter- knyta medicinen till dess antika grekiska ursprung. Själva ordet hälsa har ett etymologiskt ursprung med betydelsen helhet och fullständighet (Klein, 1966).

Humanistisk medicin är en vetenskaplig disciplin, men humanism är en livsåskådning och ideologi. I sådana ligger uppfattningar om de värden, som ytterst bör vara bestämmande för vårt liv. Varje livsåskådning grundar sig på en tro av något slag. Det ligger i sakens natur att den inte kan bevisas vara rätt eller fel, eftersom den inte vilar på vetenskaplig grund. Humanismens tro är en tro på människan. Det behöver inte vara en tro på människans naturliga godhet, men det är en tro på människans möjlighet till det goda. En religiös humanism anser att människan tillhör en högre livsordning än naturens. En profan humanism inordnar människan i naturens värld, men betecknar henne där som det högsta och mest värdefulla, det som vi mer än något annat måste värna om. Men humanismen är ingalunda oproblematisk, vilket är tydligt bland annat i synen på djurens rätt och medicinska djurförsök. Omvänt problematiskt blir det om manställerfrågan: Varförär detbarmhärtigt att avliva ett lidande djur men inte en människa? Humanistisk medicin har sålunda förutom sin rent vetenskapliga sida också en värderande, normativ del. Detta delar den med ex.vis den medicinska etiken. En del humanister brukar också hävda att deras vetenskap (er) också har ideologiska aspekter (Liedman, 1980, Ohlsson, 1992). Det avgörande i det sammanhanget är att man klart och tydligt redovisar vad som är strikt vetenskap och vad som är ideologi och värderingar. Man får så att säga inte gömma sig under den vetenskapliga objek- 
tivitetens täckmantel, något som Gunnar Myrdal(1968) gjort tydligt i sin bok Objektivitetsproblemet i samhällsforskningen. Man måste fråga sig om det existerar värdeneutral vetenskap? En av den medicinska vetenskapens förgrundsgestalter på 1800-talet, Rudolf Virchow, hävdade till skillnad från andra ledande naturforskare att det innersta av vetenskapen var ideologisk neutralt. Virchow såg uppenbart inte "kampen" mellan materialism och idealism. Det viktiga är att värderingarna inte styr resultaten, men man kan inte frigöra sig från att värderingarna påverkar frågeställningarna.

Medicinsk naturvetenskaps målsättning är att inhämta kunskaper om människans materiella biologi och medicinsk humanvetenskaps målsättning är att skaffa kunskaper och insikter för att erhålla en fördjupad helhetssyn på människans komplexitet i hälsa och sjukdom. Det finns uppenbart risker med ideologi, såväl synlig som dold. Samtidigt är ideologi ofrånkomlig om det inte finns värdeneutral vetenskap. Trots alla invändningar är humanism en möjlig ideologi för medicin och sjukvård. Idékärnan i en humanistiskt färgad medicin är insikten om att människan är mångtydig och inte låter sig fångas eller beskrivas med ett enda synsätt eller en metod. Den är med andra ord anti-dogmatisk och anti-konformistisk. En humanistisk ideologi tillämpad i sjukvården har inga givna sanningar att bistå med, men förespråkar att alltid sätta människan $i$ centrum och hävdar ett absolut människovärde, lika för alla. Det betyder att humanismen som ideologi definierar kränkning som en handling som bortser från eller åsidosätter detta absoluta människovärde. Detta skall man dock inte se som en dogmatism i sig, utan snarare som något axiomatiskt. Ett axiom kan till skillnad från en dogm modifieras och förändras efter diskussion och förnyad konsensus.

\section{Den moderna medicinens kris}

Eftersom inte all medicin är humanistisk finns det en antihumanistisk medicin, eller åtminstone en medicin med bristandehumanism, något som inte så sällan det senaste decenniet påtalats i de ledande internationella medicinska facktidskrifterna. I en aktuell avhandling har Eklöf (2000) påtalat att medicinen nästan alltid ansett sig vara $i$ en kris. I oro över det slutande 1900-talets antihumanism i samhället har en tänkare som Julien Green talat om »flockmentaliteten, den programmatiska utplåningen av all individualitet, det politiskt korrektas herravälde, det konstnärliga skapandets likriktning“ (Malmberg, 1998). En antihumanism med dessa förtecken är ett hot mot såväl läkekonst som kreativitet i medicinsk forskning. Med samma argumentation kan man kalla exempelvis nazi-medicinen eller den marxistiska medicinen för anti-humanistiska. Deras främsta mål var inte varje enskild persons bästa. Harald Ofstad har i sin kända bok Vårt förakt för svagheten beskrivit en icke-humanistisk människosyn som ser skillnader mellan människors värde. Nyttoprincipen, vanlig inom nutida vårdetik, äger alltså i sig en viss motsättning till humanism. Att hävda att ett liv som frisk är mer värt än ett liv som sjuk innebär en en anti-humanistisk hållning. Humanism i sjukvården är inte självklar och har aldrig varit det. Den kan ha olika utformning och 
tycks också i vissa avseenden vara tidsbunden. Det har kallats en humanistisk hållning att exempelvis ha en paternalistisk syn på medmänniskorna. Många av 1900-talets stora humanistiska läkare såsom Albert Schweitzer och William Osler går knappast fria från paternalism. Den hippokratiska traditionen har klara paternalistiska drag. Humanism är något vi ständigt måste resonera om. Kanske är det också något ständigt undflyende. Därutöver är det ett notoriskt mångtydigt begrepp.

Den moderna medicinens kris framtecknas ibland som en paradox. Orsaken att den ges formen av en paradox är att modern medicin räddar fler liv än någonsin tidigare i historien, men samtidigt är människorna mycket missnöjda. Antalet anmälningarökar och massmediernas negativa uppmärksammande av vårdens misslyckanden är legio.
Sekularisering, upplysthet, avsaknad av auktoritetstro finns med i den komplexa orsaksbakgrunden, liksom svårigheterna för modern medicin att handskas med såväl kronisk som funktionell sjukdom (sjukdom utan påvisbara biologiska avvikelser). Som orsak eller konsekvens växer nya professioner med annan inriktning än den strikt biologiska fram. Intresset för alternativ medicin och folkliga, icke-västerländska helandetraditioner ökar liksom problemen med bristande compliance (följsamhet till ordinationen) och skenande sjukvårdskostnader. Tanken på följsamhet i detta sammanhang är för övrigt delvis en paternalistisk relikt.

Kanske finns bland orsakerna till den moderna medicinens kris konsekvenser av en strikt naturvetenskaplig vetenskaps- och människosyn, svårförenlig med en humanistisk hållning.

\section{Litteratur}

Böttiger, L-E och Nordenström, J., red. (1999) $\AA$ herregud, mitt i semestern, Stockholm: Karolinska University Press.

Egonsson, D. (1999) Filosofiska essäer om människovärde, Nora: Nya Doxa förlag.

Eklöf,M. Läkarensethos. Studieridensvenskaläkarkårensidentiteter, intressen ochideal 1890-1960. Linköping Studies in Arts and Sciences 216, Linköping 2000.

Hedenius, I. (1982) Om människovärde, Stockholm: Bonniers förlag

Horgby, I. (1995) Begreppet person. En essä om en kristen uppfinning. i Liss, P-E och Petersson, B. red. Hälsosamma tankar, Nora: Bokförlaget Nya Doxa.

Jersild,PC(1993) Attformulerasittmänniskovärde, i Statens Medicinsk-Etiska Råd: Det svårfäng- ade människovärdet - en debattskrift. Etiska vägmärken 4 . Stockholm.

Klein, E. (red) (1966) A Comprehensive Etymological Dictionary of the English Language, vol 1, Amsterdam: Elsevier.

Ledermann, E.K. (1986) Philosophy and medicine, rev ed. Cambridge: Gower university press.

Liedman, S-E (1980) Surdeg. En personlig bok om idéer och ideologier. Stockholm: Författarförlaget.

Malmberg, C-J. (1998) Mellan sinnlighet och disciplin, recension, Svenska Dagbladet 980716.

McKerlie, D (1992) Equality between Age-groups, Philosophy \& Public Affairs 1992, vol 21, nr 3.

Myrdal, G. (1968) Objektivitetsproblemet i samhällsforskningen, Stockholm: Rabén och Sjögrens förlag. 
Nordenfelt, L. (1991) Hälsa och värde, Stockholm: Thales förlag.

Ohlsson, R. (1992) Vad är humaniorabra för egentligen?, i Bondesson, T., Edström, B., Lindmark, G., red. Humaniora i samhället, Stockholm: Liber.

Pound, E. (1975) Litterära essäer. Lund: Cavefors förlag, s. 78.

Sjöstrand,L. (1998) Hippokrates etik ger vägledning än idag, Läkartidningen 1998; 12: 1303-1306.

SOSFS 1996:24

SOU (1993) Vårdens svåra val, 1993:93.

Statens Medicinsk-Etiska Råd(1993): Det svårfångade människovärdet - en debattskrift. Etiska vägmärken 4. Stockholm

Stolt, C-M. (1999) Humanistisk medicin. Försök till ämnesbeskrivning. HIS-rapport, Karolinska Institutet, Stockholm.

Strömberg, U-B. (1999) Människors värde och värdighet i svensk historia frän 1850 till nutid. Konferensrapport. Örebro: Humanistic Studies at the University of Örebro 3.

Sundström, P. (1996) Sjukvårdens etiska grunder. Göteborg: Daidalos förlag.

Tännsjö, T. (1990) Vårdetik, Stockholm: Rabén och Sjögren.

\section{Summary \\ Medicine and the value of life}

The article discusses the components of everyday ethics in medical practice. There is an obvious need to discuss the attitude of general ethics within the public medical service. Important tools for deepening the discussion are philosophical analysis of concepts and the history of ideas and science. In this paper the most common and important concepts of general ethics are analysed. These are also put in relation to a model of medicine as a system of knowledge. Finally, humanism is focused on as an ideology for medicine and the public medical service.

Our conception of the world and our view of science influence or even govern the way we regard and view mankind. In our view of mankind there are evaluating, normative elements. All these comprehensive concepts are affected by ideologies, more or less obvious. The ideology emphasized in this paper is humanism, since it seems to be generally referred to in public medical service and medicine today. One part of the view of mankind is the idea of the value of life. Is it the same for all of us? Is value of life absolute or relative? Most people today seem to hold the former alternative as self-evident, i.e., it is claimed to be a normative axiom. An absolute value of life is invariable. A relative value of life varies and is perhaps even possible to influence.

In the ethical discussion of the medical service it is common to consider whether the degree of autonomy influences the value of life, or in other words, whether a person's disease influences his or her value of life. A relative, varying value is connected to whether one views man as an actor rather than as a person. This difference in the view of mankind is conditioned by one's view of man as having an absolute greatness or as someone who can act or participate. The connections are as obvious between ethics of virtue and the concept of being a person, 
as between ethics of utility and the concept of being an actor.

When does one become a human being and when does one cease to be one? What consequences are to be seen from discussing value of life for the fully autonomous and a quality of protection for the not fully autonomous? Is it a gradual process to become or cease to be a human being? Autonomy and integrity are empty concepts if one does not emphasize the threats against them. The most dangerous threat can be summed up in one word: violation. Violation means not respecting autonomy, integrity and quality of life, in fact not respecting the person as such. It is important to remember that violation can be characterised as unaware or deliberate, systematic or spontaneous.

When discussing these basic, general ethi- cal concepts in public medical care it feels urgent to incorporate them into a model for medicine as a system of knowledge and practice. I consider the term medicine an appropriate concept from the point of view of principal. Its most profound purpose is to describe, explain and understand man in sickness and health, in order to help. This definition is perhaps too broad, but can be used for lack of better ones. In its practice, medicine is both an art and a science. The art performed is that of healing, which is the personal art of understanding used in relation to the patient. The science used in medical care can consequently be called medical science, and it consists in part of science, and in part of humanities (human science). A closer distinction between the two is made in the paper. 